\title{
Administración Pública dialógica: en busca de la CONCRETIZACIÓN ISONÓMICA DE DERECHOS FUNDAMENTALES EN BRASIL
}

\section{Dialogic Public Administration: in search of social fundamental RIGHTS ISONOMIC CONCRETIZATION IN BRAZIL}

Fernanda Schuhli Bourges*

Trabajo recibido el 30 de noviembre de 2018 y aprobado el 4 de diciembre de 2019

\begin{abstract}
Resumen
El presente artículo, a partir del reconocimiento de la aplicabilidad inmediata de los derechos fundamentales sociales y teniendo en cuenta que la Constitución de la República de Brasil establece un Estado Democrático y Social de Derecho y, considerando el deber constitucional de la Administración de implementar esos derechos, presenta la posibilidad de la adopción de mecanismos de diálogo en la actuación administrativa, a fin de compatibilizar la Administración Pública con la Constitución, especialmente para que, a partir de participaciones sociales dialógicas, se concreten los derechos fundamentales sociales anticipadamente y de forma isonómica, en sus dimensiones subjetivas y objetivas. La propuesta tiene como presupuesto la constatación del volumen de demandas judiciales con el fin de concretar derechos fundamentales sociales, pero dichas decisiones producen efectos a menudo no isonómicos y con reducido potencial de concreción de derechos fundamentales sociales. Así es que, a partir del método hipotético-deductivo, se presenta la Administración Pública dialógica con la utilización de procedimientos democráticos de diálogo con la colectividad, para que puedan ser cosechadas las reales necesidades y eventuales soluciones a la concretización anticipada e isonómica de los derechos fundamentales sociales, especialmente en su dimensión objetiva.
\end{abstract}

Palabras clave: Administración Pública; Derechos Fundamentales Sociales; diálogo.

\begin{abstract}
This article, from the recognition of the immediate applicability of fundamental social rights and considering that the brazilian's Constitution establishes a Republic Democratic and Social State of Right and, considering the constitutional duty of the Administration to implement those rights, presents the possibility of the adoption of dialogue mechanisms in the administrative action, in order to make the Public Administration compatible with the Constitution, especially so that, based on dialogical social participa-

\footnotetext{
* Fernanda Schuhli Bourges. Doctoranda en Direito Econômico e Desenvolvimento por la Pontifícia Universidade Católica do Paraná - PUC/PR (Curitiba, Paraná, Brasil); Mestre em Direito do Estado por la Universidade Federal do Paraná - UFPR; Especialista en Direito Administrativo por el Instituto de Direito Romeu Felipe Bacellar; Professora de Direito Administrativo y membro del Conselho de Administração da Faculdade de Educação Superior do Paraná - FESP/PR; Membro da Comissão de Gestão Pública, Controle e Transparência junto à OAB/PR desde 2007; Abogada. Correo de contacto: ferbourges@yahoo.com.br, fernanda@blanchet.adv.br.
} 
tion, the social fundamental rights may be concretized in advance and isonomically, in their subjective and objective dimensions. The purpose is based on the intensive volume of lawsuits with the aim of fundamental social rights achievement, but those decisions oftenly present non-isonomic effects and with little fundamental social rights realization potential. Thus, from the hypothetical-deductive method, the Dialogical Public Administration is presented with the use of democratic procedures of dialogue with the community, so that the real needs and possible solutions can be harnessed to the anticipated and isonomic accomplishment of the fundamental social rights, especially in its objective dimension.

Keywords: Public Administration; Fundamental Social Rights; Dialogue.

\section{INTRODUCCIÓN}

El artículo pretende presentar la posibilidad de que la Administración Pública convierta su modo de gestión hacia una forma dialogada, más democrática, como uno de los medios posibles para la concreción de los derechos fundamentales sociales en sus dimensiones subjetiva y objetiva con isonomía.

En este sentido, se tratan consideraciones respecto a los derechos fundamentales sociales, así como sobre la judicialización de estos derechos, muchas veces derivada de la actuación administrativa obsoleta, aislada de la sociedad y apegada a la legalidad estricta, que acaba por no realizar satisfactoriamente los derechos fundamentales sociales.

Se propone reflexionar sobre los efectos de la judicialización de los derechos fundamentales sociales, ya que, según el enfoque, pueden representar mayor dificultad a la concreción isonómica de tales derechos.

El Poder Judicial tiene la prohibición de non liquet, pero muchas decisiones no se muestran efectivas a la concreción de derechos fundamentales, restringiéndose, por regla general, a un individuo circunstancialmente.

Así pues, reconociendo la efectividad de la Constitución de la República, así como la aplicabilidad inmediata de los derechos fundamentales, englobados los sociales, se tiene que la Administración Pública tiene el deber de realizar referidos derechos y, teniendo en cuenta el Estado Democrático de El derecho, así como el modelo de gestión pública de índole legalista y liberal comúnmente adoptado, la propuesta es presentar la posibilidad y las posibles ventajas de una relectura de la Administración Pública para un modelo de gestión dialógica, con la adopción de procedimientos democráticos de diálogo con la política para que puedan cosecharse las reales necesidades y eventuales soluciones a la concreción anticipada e isonómica de los derechos fundamentales sociales, tanto en su dimensión subjetiva, como, y principalmente, objetiva.

\section{DeReChOS fundamentales SOCIALES: MULTIFUNCIONALIDAD, DimENSIONES SUBJETIVA Y OBJETIVA Y APLICABILIDAD INMEDIATA}

Diversos Estados, especialmente el Brasil, adoptan un modelo constitucional típico del Estado Social y Democrático de Derecho, característico del post Segunda Guerra Mundial y de las sociedades industrializadas en el siglo XX, que configura un constitucionalismo social y no sólo liberal, con la consagración de

SCHUHLI BOURGES, Fernanda. Administración Pública dialógica: en busca de la concretización isonómica de derechos fundamentales en Brasil. Revista Justicia y Derecho, Santiago, v. 2, n 2, 2019 
derechos sociales con el fin de lograr la igualdad sustancial y preservar la dignidad humana'.

Así, la Constitución pasó a disciplinar derechos económicos y sociales, además de derechos de libertad e igualdad y tratan del individuo como perteneciente al Estado y no en oposición a éste, como en el constitucionalismo liberal. Aún, se reconoce la fuerza normativa de la Constitución y la demanda por la efectividad de los derechos fundamentales, con énfasis a los sociales ya la dignidad de la persona humana. Se trata de lo que se denomina "neoconstitucionalismo" en que la Constitución pasa a tener superioridad ya actuar como parámetro de validez y se enfatiza también el control de constitucionalidad, así, se adentra en un nuevo paradigma, el sistema normativo, se basa en la dignidad de la persona humana y en los derechos fundamentales que emanan de ella. De modo que el derecho constitucional pasa a tener el énfasis de la efectividad, con la preocupación de obtener eficacia jurídica y asegurar la eficacia social de las disposiciones constitucionales. ${ }^{2}$.

No obstante, los enunciados normativos de los derechos fundamentales sociales se caracterizan por una elevada abstracción en cuanto a su contenido, que posibilita su adecuación conforme el tiempo, el espacio y las demás contingencias, pero tal abstracción muchas veces dificulta su concreción y genera mayores controversias y judicialización.

Al respecto, el aspecto que distingue los derechos sociales de los derechos de libertad, según Jorge Reis Novais, es que la Constitución no puede o no debe fijar los límites de los derechos sociales y, de este modo, estos se diferencian de los de libertad por su naturaleza, estructura y fuerza jurídica³.

Sin embargo, independientemente de si se trata de derecho social, posee la misma protección jurídica de un derecho de libertad, se constituye en una garantía jurídica constitucional, que debe ser observada por el poder político. Siendo que esta garantía constitucional asume mayor relevancia en Estados con exclusión social significativa y problemas de desarrollo para la construcción del Estado de Democrático de Derecho ${ }^{4}$.

Jorge Reis Novais plantea que la distinción entre derechos de libertad y sociales no puede ser analizada como si hubiera dos paradigmas -derecho privado y derecho social- como si hubiera ocurrido una superación pues, al contrario, el Estado Social de Derecho acoge el Estado de Derecho Liberal y, según el autor, ejemplo es el derecho de libertad a la huelga 5 .

Es equivocado enlazar los derechos fundamentales sociales a las prestaciones y los de libertad a las abstenciones, pues los derechos sociales pueden requerir prestaciones y, por lo tanto, serán positivos o pueden configurar derechos de defensa y, de ese modo, serán negativos. Todos los derechos fundamentales reúnen concomitantemente la totalidad de los rasgos que supuestamente serían propios a cada una de las generaciones, es decir, imponen deberes, dirigen obligaciones al Poder Público y ostentan doble titularidad - individual y transindividual ${ }^{6}$. Además, la Constitución previó derechos sociales esencialmente negativos como el derecho de huelga?.

Además, de un mismo texto normativo pueden extraerse diversas normas de derechos fundamentales, que pueden invertir a los individuos y la colectividad en distintas posiciones jurídicas ${ }^{8}$.

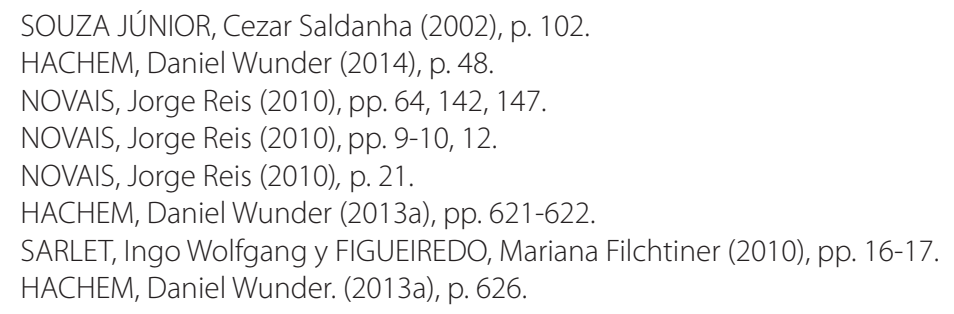

SCHUHLI BOURGES, Fernanda. Administración Pública dialógica: en busca de la concretización isonómica de derechos fundamentales en Brasil. Revista Justicia y Derecho, Santiago, v. 2, n 2, 2019 
Romeu Felipe Bacellar Filho ilustra esa posibilidad de diversidad de posiciones a partir de lo dispuesto en el art. De la Constitución de la República, según el cual "nadie será sometido a tortura ni a trato inhumano o degradante", y que nos remite, primero, a un derecho negativo, de abstención y protección. Sin embargo, si se piensa en la hipótesis de un enfermo, con fuertes dolores, sin atención, no hay dudas acerca de la violación de la dignidad de la persona humana, y la configuración de tortura, trato inhumano o degradante, lo que demanda prestaciones positivas?.

En la Constitución brasileña se reconoce que todos los derechos sociales son fundamentales y, así, tienen como característica la doble fundamentalidad formal y material de los derechos fundamentales y también gozan de la máxima eficacia y efectividad, en los términos del art. 5, §1 de la Constitución ${ }^{10}$.

Se reconoce también otra peculiaridad a los derechos fundamentales, que es la estructura normativa bidimensional o la multifuncionalidad ${ }^{11}$, una vez que confieren posiciones subjetivas a sus titulares para exigir conductas positivas o negativas del Estado y prevean deberes objetivos al Poder Público para que éste establezca condiciones al usufructo, protección e implementación de estos derechos de modo general, una vez que los derechos fundamentales sociales son indispensables al desarrollo de la personalidad de los individuos y están concebidos como elemento de la libertad².

La dimensión objetiva de los derechos fundamentales se desarrolla en los Estados Sociales y Democráticos de Derecho en el período posguerra, como un orden objetivo de valores que legitima el sistema jurídico del Estado y condiciona la actuación de los poderes ${ }^{13}$.

Como efectos jurídicos concretos del reconocimiento de la dimensión objetiva de los derechos fundamentales se destaca la eficacia irradiante de tales derechos por todo el ordenamiento, de modo que condicionan la interpretación y la aplicación de las normas, así como la imposición al Poder Público de "deberes autónomos de" protección ", independientemente de cualquier solicitud y de correspondencia con alguna pretensión subjetiva ${ }^{14}$.

Es importante resaltar que los derechos fundamentales en la acepción subjetiva no se confunden con el derecho subjetivo, pues el titular del derecho fundamental no es sólo el individuo, sino también un grupo específico o la colectividad indeterminable. Así, la titularidad de derechos fundamentales sociales también es transindividual ${ }^{15}$.

Los derechos sociales, ya que son derechos fundamentales constitucionales, pertenecen al régimen de los derechos fundamentales, con fuerza normativa superior y no se delimitan al "mínimo social"16.

El papel del Estado frente a los derechos sociales es multifuncional y puede representar el deber de respetar, proteger o promover el acceso, y todas estas posiciones implican costos. Ocurre que gran parte de la población no tiene condiciones de acceder a los bienes de los derechos fundamentales sociales, por lo que se suele asociar tales derechos a la promoción del acceso ya los costos directos ${ }^{17}$.

9 BACELLAR FILHO, Romeu Felipe (2014), p. 253.

10 SARLET, Ingo Wolfgang y FIGUEIREDO, Mariana Filchtiner (2010), pp. 18-19.

11 HACHEM, Daniel Wunder (2013a), pp. 624, 627-628.

12 Conforme contribución de la teoría social de los derechos fundamentales defendida por Alexy. ALEXY, Robert (2007), p. 499.

Apud: HACHEM, Daniel Wunder (2013a), p. 638.

13 NOVAIS, Jorge Reis (2003), 2003, pp. 57-58.

14 HACHEM, Daniel Wunder (2013a), p. 640; NOVAIS, Jorge Reis (2003), pp. 68-70; ALEXY, Robert (2014), p. 491.

15 Conforme HACHEM, Daniel Wunder (2013a), pp. 632-633.

16 NOVAIS, Jorge Reis (2010), p. 84.

17 NOVAIS, Jorge Reis (2010), p. 42-43.

SCHUHLI BOURGES, Fernanda. Administración Pública dialógica: en busca de la concretización isonómica de derechos fundamentales en Brasil. Revista Justicia y Derecho, Santiago, v. 2, n 2, 2019 
De este modo, en un Estado con tanta desigualdad y falta de condiciones mínimas al mantenimiento de la dignidad, las demandas son innumerables y variadas y una de las grandes dificultades a la concreción de los derechos sociales es el aspecto económico, especialmente en lo que se refiere a las prestaciones $^{18}$. Esta necesidad de recursos financieros, ante la escasez de éstos, exige la elección de prioridades y definición de opciones políticas para la realización de los derechos sociales ${ }^{19}$.

Se considera que como consecuencia de la fuerza normativa de la Constitución, así como de la aplicabilidad inmediata de los derechos fundamentales, incluidos los sociales, el Poder Público tiene el deber de concretar los derechos fundamentales sociales, independientemente de la provocación, administrativa o judicial, individual o transindividual, porque su deber no se restringe sólo a la dimensión subjetiva; comprende también la dimensión objetiva de los derechos fundamentales y, por lo tanto, debe realizar tales derechos de oficio ${ }^{20} \mathrm{y}$, si los recursos son escasos, debe obedecer la igualdad y la necesidad en la concreción de estos derechos ${ }^{21}$.

\section{LA EXCESIVA JUDICIALIZACIÓN Y LA SUPUESTA REALIZACIÓN DE LOS DERECHOS SOCIALES}

A pesar de la Constitución garantizar numerosos derechos y prever obligaciones de realizaciones al Estado y teniendo en cuenta lo dispuesto en el art. 5, §1 ${ }^{\circ}$, que otorga aplicabilidad inmediata a los derechos fundamentales, se ha vivido y aún se constata una gran contradicción con la práctica legislativa y ejecutiva de la baja efectividad a tales derechos, lo que acabó por propiciar el elevado número de demandas judiciales en busca de la demanda realización subjetiva de derechos fundamentales ${ }^{22}$.

En principio, la jurisprudencia no reconocía, o admitía en casos específicos, la fuerza normativa de los derechos sociales, sin embargo, con el paso de los años, hubo cambio en la orientación jurisprudencial, se admitieron las posiciones subjetivas y la sindicabilidad de los derechos sociales, así, se pasó a condenar a la Administración -hasta de forma indiscriminada y no criteriosa- a conceder las pretensiones postuladas ante el Poder Judicial, sobre todo en materia de derecho a la salud²3.

Sin duda, los derechos fundamentales sociales son pasibles de sindicalización e implementación por el poder judicial, pero la problemática se refiere al excesivo número de demandas judiciales -lo que posibilita constatar la falta de efectividad de tales derechos que debían ser concretizados por los demás poderes- ya los efectos de gran parte de las sentencias dictadas en estos casos.

Aunque los derechos sociales involucran las dimensiones positivas y negativas, sin duda prevalece la dimensión positiva, que demanda la asignación pública de recursos limitados, además del hecho de ser constitucionalmente más indeterminados que los derechos de libertad, hechos éstos que acaban por propiciar dificultades en la concreción de estos derechos.

El Poder Público elige prioridades en la atención de los derechos sociales, especialmente en sus dimensiones positivas, en general, más costosas y, como resalta Jorge Reis Novais, las elecciones y opciones políticas de distribución de recursos pueden generar conflictos ${ }^{24}$.

18 SARLET, Ingo Wolfgang y FIGUEIREDO, Mariana Filchtiner (2010), p. 27.

19 NOVAIS, Jorge Reis (2010), p. 59.

20 De forma espontánea, integral e igualitaria, según defiende HACHEM, Daniel Wunder (2014).

21 NOVAIS, Jorge Reis (2010), pp. 49-50.

22 HACHEM, Daniel Wunder (2013b), pp. 345-349.

23 HACHEM, Daniel Wunder (2014), p. 49.

24 NOVAIS, Jorge Reis (2010), pp. 115-116.

SCHUHLI BOURGES, Fernanda. Administración Pública dialógica: en busca de la concretización isonómica de derechos fundamentales en Brasil. Revista Justicia y Derecho, Santiago, v. 2, n 2, 2019 
Otra dificultad enfrentada se refiere a la identificación de las reales necesidades y posibles soluciones para atenderlas ante la heterogeneidad de las demandas, de intereses diversos y contradictorios, así como de la complejidad y tecnicidad involucradas. Además de la reserva de lo financieramente posible y de lo políticamente oportuno, que acaban justificando muchas veces la no realización de los derechos sociales ${ }^{25}$.

El fenómeno del aumento del número de demandas judiciales se deriva del hecho de que los ciudadanos no aceptan más esperar las prestaciones estatales para asegurar la dignidad y, de ese modo, buscan al Poder Judicial para garantizar los derechos fundamentales que no fueron realizados por el Poder Ejecutivo, de cuestiones operativas o presupuestarias ${ }^{26}$.

Se observa que el Poder Judicial, con vistas a la separación de poderes, difícilmente puede controlar la prevalencia de las razones contrarias a la realización de un derecho social por cuestiones financieras ${ }^{27}$. Uno de los problemas de la judicialización de los derechos sociales es que las demandas suelen ser individuales y concretas y la controversia del derecho social no es presentada como un todo, lo que acaba por fallar en la real concreción de los derechos sociales del propio demandante y, aún, generar repercusiones negativas contra los potenciales beneficiarios y la colectividad.

Jorge Reis Novais resalta que el Judiciario es invadido por acciones individuales dirigidas a prestaciones específicas, comúnmente en lo que se refiere a la salud, con gran impacto en los fondos disponibles para todo el sector y, así, las imposiciones judiciales concretas pueden generar retroceso en las políticas de salud ${ }^{28}$.

El Poder Judicial, hasta entonces, era aparcado para actuar sobre hechos ocurridos, pretéritos e individuales o restringidos, mientras que la naturaleza de las demandas propuestas actualmente es prospectiva, relativa al futuro y, en gran parte, con repercusiones difusas o colectivas. Se busca una decisión judicial transformadora, prospectiva, y, tal decisión, que expide determinaciones al administrador, para ser legítima, debe ser acompañada de los resultados que se pretende alcanzar, lo que demanda un repensar de la actuación jurisdiccional ${ }^{29}$.

En un ambiente donde los conflictos son complejos, se evidencia que la Corte Suprema brasileña, que no suele distinguir si el derecho fundamental perseguido ya es objeto de alguna política pública existente o en marcha, tiene ante sí la necesidad de efectuar una elección el respeto de un diseño institucional ${ }^{30}$. Ocurre que, formular políticas públicas y concretar derechos fundamentales sociales presupone la elección de prioridades y decisiones estratégicas, de carácter administrativo, que envuelve elementos distintos que simplemente enunciar la dignidad de la persona humana como objetivo fundamental de la República. Falta al Poder Judicial los datos necesarios para la gran gama de opciones de la realidad administrativa ${ }^{31}$.

Vanice del Valle, tras analizar una serie de decisiones judiciales brasileñas acerca de las políticas públicas y derechos fundamentales, diagnostica innumerables dificultades y problemas que pueden surgir a partir de tales decisiones judiciales en estas demandas complejas. El Poder Judicial se convierte en un "veto player", es que puede bloquear las actuaciones previamente establecidas por el Poder Público debi-

25 NOVAIS, Jorge Reis (2010), pp. 151-152.

26 BARBOZA (2007), p. 149.

27 NOVAIS, Jorge Reis (2010), p. 107

28 NOVAIS, Jorge Reis (2010), p. 27.

29 VALLE, Vanice Regina Lírio do (2016), pp. 112, 152-153.

30 CARVALHO, Flávia Martins de, VIEIRA, José Ribas y RÉ, Mônica Campos de (2009) pp. 84-85.

31 VALLE, Vanice Regina Lírio do (2016), p. 140 
do al reajuste de recursos, de modo que el cumplimiento de la decisión judicial puede ocasionar efectos negativos bajo el aspecto social ${ }^{32}$.

La alerta de Vanice del Valle en cuanto a la efectividad de las actuales decisiones judiciales en políticas públicas y derechos fundamentales es relevante para la reflexión acerca del modelo hasta entonces adoptado y de la necesidad de repensarlo. Aunque la decisión judicial asegure una prestación específica y contingente, no posibilita el desarrollo de la política pública, o sea, no beneficia a la colectividad, por lo que la provisión no garantiza la efectividad de los derechos fundamentales ${ }^{33}$. Además, algunas decisiones judiciales determinan la reubicación de grandes recursos públicos a la atención de un solo caso, en evidente afrenta al principio de igualdad pues hasta puede haber recursos para la atención de aquel caso individual, pero no para los demás potenciales necesitados de la misma providencia o de distintas, tan o más relevantes que la que obtuvo la provisión judicial ${ }^{34}$.

Así, la concreción de derechos fundamentales sociales por el Poder Judicial, a pesar de ser benéfica al autor de la acción, sólo concreta la dimensión subjetiva e individual -teniendo en vista que gran parte de las demandas son individuales- en potencial perjuicio a los demás titulares de idéntico derecho, en afrenta a la igualdad, y en cierto perjuicio a la concreción de la dimensión objetiva de los derechos fundamentales sociales. De modo que la concreción por la vía judicial tiende a fomentar la desigualdad social y la falta de respeto del interés público, ya que la condena judicial del Poder Público, en relación con los aspectos positivos de los derechos, se refiere a la reubicación de recursos públicos, de la colectividad.

De este modo, a pesar de que el recurso al Poder Judicial muchas veces es la única posibilidad, la concreción de los derechos sociales por la vía jurisdiccional, acaba por beneficiar sólo a los demandantes, por lo tanto, de forma desigual. La realización de los derechos fundamentales sociales debe respetar la igualdad y promover la reducción de las desigualdades, objetivo fundamental de la República. Con la excesiva judicialización se suele tener una profundización de la desigualdad ${ }^{35}$.

Se extrae que la efectividad plena de los derechos fundamentales sociales, indispensable al logro de los objetivos de la República, no será alcanzada solamente por intermedio del Poder Judicial, se hace necesaria la "actuación programada de una Administración Pública inclusiva"36.

\section{Actuación administrativa dialógica: UNa posibilidad a la CONCRECIÓn ISONÓMICA DE LOS DERECHOS FUNDAMENTALES SOCIALES}

Se diagnostica un desajuste entre la Constitución Democrática y Social y el modo de gestión pública aún adoptado, con profundas raíces en el modelo administrativo del siglo XIX, una vez que la Administración actúa unilateralmente, muchas veces, arbitrariamente, por lo que los individuos todavía necesitan

32 VALLE, Vanice Regina Lírio do (2016), p. 150.

33 VALLE, Vanice Regina Lírio do (2016), p. 111

34 Es posible visualizar la desigualdad en la efectividad de derechos sociales con la excesiva judicialización a partir del siguiente ejemplo presentado por Daniel Hachem "En el Estado de Minas Gerais en 2010. De los R \$ 360.029.986,11 gastados con suministro de medicamentos básicos y de alto costo por el costo El Estado, el valor de R\$55.052.215,84 fue destinado al cumplimiento de decisiones judiciales de esa naturaleza, beneficiando un total de 4.762 pacientes en un Estado con 19.595 .309 habitantes. Significa que sólo el 0,024\% de los ciudadanos del Estado, que manejaron acciones judiciales para garantizar el acceso a esos bienes, abarcaban aproximadamente el 15,3\% del total presupuestario gastado en la distribución de medicamentos." (Traducción de la autora). HACHEM, Daniel Wunder (2014), p. 51.

35 HACHEM, Daniel Wunder (2014), p. 52.

36 HACHEM, Daniel Wunder (2014), p. 127.

SCHUHLI BOURGES, Fernanda. Administración Pública dialógica: en busca de la concretización isonómica de derechos fundamentales en Brasil. Revista Justicia y Derecho, Santiago, v. 2, n², 2019 
de instrumentos de defensa, sin embargo, ese Derecho Administrativo oitocentista "ya no es capaz de dar cuenta de todas las exigencias de la sociedad contemporánea, suscitadas con el advenimiento del Estado Social y Democrático de Derecho37.

Se defiende un derecho administrativo social, de modo que el fin del derecho administrativo es la defensa, promoción y protección de los derechos fundamentales de la persona-comprendidos los sociales ${ }^{38}$, he aquí que, según Rodríguez-Arana Muñoz, corresponde a la Administración, en la mayor medida, la realización del contenido del Estado Social ${ }^{39}$.

Se hace evidente la desactualización del Derecho Administrativo ${ }^{40}$, que no se utiliza de los más variados instrumentos que posibiliten alcanzar la eficiencia administrativa y la concreción espontánea de los derechos fundamentales sociales, independientemente de interpelación judicial provocada por algún individuo ${ }^{41}$.

Una vez que el Derecho Administrativo se presenta como el Derecho Constitucional concretado, la actuación administrativa debe corresponder a lo dispuesto en la Constitución ${ }^{42}$; debe representar la Constitución en acción ${ }^{43}$.

Además, el desajuste del derecho administrativo no ocurre sólo en relación a la Constitución, también se verifica ante la complejidad de las demandas de distintos segmentos sociales y de las posibles soluciones en razón de las nuevas necesidades, tecnologías disponibles, relaciones jurídicas innovadoras, nueva dinámica y velocidad, etc., de modo que los instrumentos hasta entonces utilizados por la Administración Pública no atienden gran parte de la demanda de la colectividad debido a las contingencias de la realidad social ${ }^{44}$. En ese escenario, debe ser repensada la actuación administrativa en prol de la efectividad de los derechos ${ }^{45}$, especialmente en lo que se refiere a la dimensión objetiva de los derechos fundamentales sociales, como modo de a concretarlos isonomicamente.

Se desprende la necesidad de adecuación y actualización de la gestión administrativa a partir de la constatación de la insuficiente concreción de los derechos fundamentales sociales por parte de la Administración Pública y de la profusión de demandas judiciales y decisiones que acaban por ofender la igualdad. La Administración debe volver a la satisfacción de los derechos fundamentales sociales y hacer efectiva la Constitución. Reconociendo el Estado como social, se determina una relectura del modo de actuar administrativo, calcado en la unilateralidad y en la imposición, para que sus objetivos sean realizados ${ }^{46}$.

\footnotetext{
37 HACHEM, Daniel Wunder (2014), p. 214.

38 RODRÍGUEZ-ARANA MUÑOZ, Jaime (2015b), p. 9.

39 RODRÍGUEZ-ARANA MUÑOZ, Jaime (2015a), p. 56

40 En este sentido Rodríguez-Arana Muñoz"Si la dignidad del ser humano y el libre y solidario desarrollo de su personalidad son el canon fundamental para medir la temperatura y la intensidad del Estado social y democrático de Derecho, entonces es llegado el tiempo en el que de una vez por todas las técnicas del Derecho Administrativo se diseñen de otra forma. De una forma que permita que los valores y parámetros constitucionales sean una realidad en la cotidianeidad. Si el Derecho Administrativo es el Derecho Constitucional concretado, no hay otro camino." RODRÍGUEZ-ARANA MUÑOZ, Jaime (2015a), p. 30.

41 HACHEM, Daniel Wunder (2014), pp. 257-258.

42 HACHEM, Daniel Wunder (2014), p. 57.

43 Según Forsthoff"la esencia misma del Derecho Administrativo como Derecho de concreción o materialización de la Constitución - la Administración pública es la Constitución en acción" (FORSTHOFF, E. Concepto y esencia del Estado social de Derecho. In: ABENDROTH, Wolfgang; FOSTHOFF, Ernst; DOEHRING, Karl (Orgs.). El Estado social. Madrid: Centro de Estudios Constitucionales, 1986) Apud: RODRÍGUEZ-ARANA MUÑOZ, Jaime (2015a), p. 41

44 XAVIER, Gabriela Costa (2014), p. 36.

45 "La cláusula del Estado social ha significado una profunda transformación en el tradicional entendimiento del Derecho Administrativo. En efecto, el Estado debe promover las condiciones para que la libertad y la igualdad de las personas y de los grupos en que se integran sean reales y efectivas, removiendo los obstáculos que impiden su efectividad y fomentando la participación de todos los ciudadanos en la vida política, económica, social y cultural." RODRÍGUEZ-ARANA MUÑOZ, Jaime (2015b), p. 11. 46 BITENCOURT NETO, Eurico (2017), p. 209.
} 
La Administración debe actuar de oficio, o provocada, orientada por la selectividad y universalidad, de modo que la concreción de derechos administrativamente propicie soluciones isonómicas. No hay razón de destinarse al Poder Judicial la concreción de los derechos que pueden y deben ser realizados en sede administrativa ${ }^{47}$.

Daniel Hachem defiende el derecho a la tutela administrativa efectiva, espontánea, integral e igualitaria de los derechos fundamentales sociales a partir de la interpretación sistemática de lo dispuesto en el art. $5^{\circ}, \S \S 1^{\circ}$ y $2^{\circ}$ y en el art. 37 de la Constitución, así como del derecho fundamental a la tutela administrativa efectiva, establecido en la Carta Iberoamericana de los Derechos y Deberes del Ciudadano en Relación con la Administración Pública, aprobada el 10 de octubre de 2013 por el Centro Latinoamericano de Administración para el Desarrollo y, así, la Administración Pública debe realizar los derechos fundamentales sociales en su totalidad, además del mínimo existencial ${ }^{48}$.

A partir del Estado Democrático de Derecho, consagrado por la Constitución de la República Federativa del Brasil de 1988, se fundamenta un movimiento doctrinario en el sentido de la democratización de la Administración Pública y en la implementación, de ese modo, de una Administración Pública Dialógica, Consensual, Concertada, que actúa mediante contratos, según algunos autores, mediante actos bilaterales o mediante acuerdos ${ }^{49}$.

La necesidad de practicar la democracia y que ésta se extiende por todo el sistema y su aplicación, para hacer efectiva la democracia del Estado y en el Estado se hace necesaria la democratización de la Administración ${ }^{50}$.

A partir del Estado Democrático de Derecho surge, así, una forma de gestión pública compartida del Estado con la sociedad..$^{51}$ Una vez que la ciudadanía y la dignidad de la persona humana constituyen fundamentos republicanos, no hay como la función administrativa desconectarse del interés de los propios ciudadanos, tanto en una perspectiva individual y colectiva ${ }^{52}$.

La Administración, de ese modo, es compelida a revisar su modelo autoritario de gestión de la cosa pública, para transformarse en un espacio de respeto, protección y promoción de los derechos fundamentales. En este sentido, la Administración Consensual actúa mediante procedimientos negociadores en sustitución, cuando sea posible, a la actuación impositiva y unilateral53.

Se rescata el deber de la buena administración, aquella que actúa de modo instrumental para el interés general y presupone al ciudadano, menos apegada al privilegio y más orientada a la mejora de las condiciones de vida, así como a la concreción de los derechos fundamentales sociales ${ }^{54}$, a reconectar la estructura estatal con el ser humano, rescatándose su objetivo ${ }^{55}$.

A partir de la participación y diálogo de la colectividad con la Administración es posible la defensa de los intereses de aquella y el suministro de subsidios para el Poder Público efectivamente atender al interés público, propiciando la realización del derecho a la buena administración ${ }^{56}$.

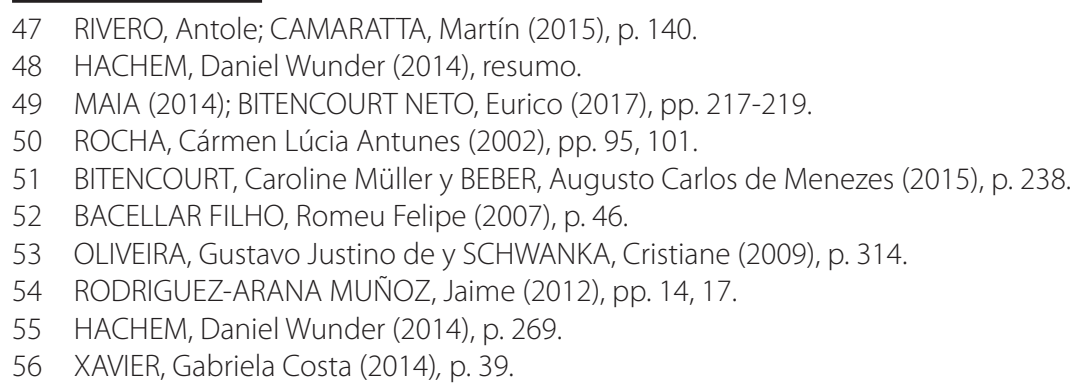


La participación administrativa posibilita la identificación del interés público de forma compartida con la población y, de ese modo, reduce la discrecionalidad, así como la unilateralidad y viabiliza la adopción de prácticas contractuales basadas en el consenso, negociación y conciliación de intereses ${ }^{57}$.

Según Sabino Cassesse ${ }^{58}$ el paradigma bipolar Estado-ciudadano cede espacio al paradigma multipolar, con múltiples agentes e interesados en la discusión de asuntos públicos, lo que demanda la celebración de acuerdos, exigiendo para tanto permutas y negociaciones.

Se alcanza la legitimidad democrática cuando la actuación estatal proviene a partir del diálogo con los integrantes de la sociedad, pues serán directamente afectados por el ejercicio del Poder Público, y presupone las deliberaciones, las discusiones y decisiones de sus miembros ${ }^{59}$.

La participación de la población, además de concretar los dictámenes constitucionales de democratización, "racionaliza la actuación administrativa, ampliando las posibilidades de concreción de las disposiciones constitucionales ${ }^{60}$.

Así, a partir del perfeccionamiento del diálogo entre la colectividad y la Administración se puede promover la implementación de los derechos fundamentales sociales, tanto en su dimensión objetiva como subjetiva y ampliar la estabilidad de las relaciones entre Estado y sociedad y cerrar o evitar litigios que suelen durar años, con la postergación de la realización de derechos y del propio interés público ${ }^{61}$.

De acuerdo con Diogo de Figueiredo Moreira Neto ${ }^{62}$, el consenso como forma de actuación estatal contribuye a la eficiencia, legalidad, justicia, legitimidad, licitud, civismo y orden.

La Administración dialógica es más acorde con la sociedad moderna, pluralista y compleja para que se pueda filtrar las demandas e investigar las posibles soluciones por intermedio de los más variados segmentos sociales, con la riqueza de la diversidad de conocimientos y experiencias.

El modelo jurídico y político que se utiliza sólo de la representatividad no es el más adecuado para la gestión del interés público. Ante la complejidad de la sociedad posmoderna, con una pluralidad de sujetos y voluntades distintas, se muestra poco viable concentrar en pocos la identificación y la ejecución de las demandas públicas ${ }^{63}$. La definición unilateral del interés público no es compatible con un Estado Social y Democrático de Derecho. La cláusula democrática exige funcionalidad de la participación social ${ }^{64}$.

La Administración Pública se hace con el público y para él, si es mero espectador teatral, será siempre una acción de pocos para pocos ${ }^{65}$.

De este modo, el interés público no debe definirse de forma unilateral y monopolizada, es necesario que la sociedad participe con su vitalidad en la definición ${ }^{66}$. La esfera pública se abre para la identificación de las necesidades de la sociedad y para el establecimiento de las soluciones ${ }^{67}$. La participación social se convierte en un parámetro de legitimación de la actuación administrativa; la imperatividad y la coerción

57 MEDAUAR. Odete (2003), p. 230.

58 La arena pública: nuevos paradigmas para el Estado. In: MEDAUAR. Odete, La crisis del Estado. Buenos Aires: Abeledo Perrot, 2003. p. 106 Apud OLIVEIRA, Gustavo Justino de y SCHWANKA, Cristiane (2009), p. 313.

59 BITENCOURT, Caroline Müller (2013), p. 85.

60 PIVETTA, Saulo Lindorfer (2010), p. 223.

61 SCHWANKA, Cristiane (2011), pp. 82-83.

62 MOREIRA NETO, Diogo de Figueiredo (2003), p. 145.

63 BITENCOURT, Caroline Müller y BEBER, Augusto Carlos de Menezes (2015), p. 250.

64 RODRÍGUEZ-ARANA MUÑOZ, Jaime (2015a), p. 52

65 ROCHA, Cármen Lúcia Antunes (2002), p. 96.

66 Conforme defiende RODRÍGUEZ-ARANA MUÑOZ, Jaime (2015b), p. 12.

67 FUNGHI, Luís Henrique Baeta (2011), p. 8. 
ceden espacio a la consensualidad ya la participación social a partir de canales de comunicación y de mecanismos consensuados ${ }^{68}$.

En la propuesta de adopción del modelo de gestión administrativa dialógica y consensual se posibilita que la Administración deje de valerse de algunos dogmas y cambie su forma de actuación en el sentido que ésta podrá resolver demandas con el ciudadano con la colectividad de forma consensuada y negociada judicial o extrajudicial. El Poder Público podrá reconocer derechos y reparar daños causados mediante diálogo con el individuo, grupos o con la colectividad, sin la necesidad de esperar por años una decisión judicial con tránsito en juzgado69. De este modo, la Administración se hará más eficaz en la concreción de los derechos fundamentales sociales, porque el tiempo y la celeridad en la aplicación de tales derechos son inherentes a su plena satisfacción. El reconocimiento tardío de un derecho puede ser inútil o poco satisfactorio.

En este sentido es la tesis de Daniel Hachem, según el cual el ciudadano tiene derecho fundamental a la tutela administrativa efectiva, "espontánea, integral e igualitaria" de sus derechos y, para ello, la Administración debe utilizar todas las técnicas y procedimientos necesarios ${ }^{70}$. Además, los derechos fundamentales pleiteados deben ser reconocidos, inclusive, mediante herramientas consensuadas de solución de controversias, como la negociación, la mediación y la conciliación, he aquí que posibilitan un diálogo a favor del consenso, prácticas que todavía contribuyen a la reducción de acciones judiciales innecesarias y promueven la realización más rápida y provechosa de los derechos fundamentales ${ }^{71}$.

En esta forma de solución y concreción administrativa de los derechos fundamentales, la Administración puede valerse de importantes instrumentos como las sumas administrativas, fundamentadas en dictámenes técnico-jurídicos y / o en precedentes jurisprudenciales, para reconocer administrativamente los pleitos de casos con las mismas pretensiones ${ }^{72}$.

No satisface el interés público la implicación del Poder Público en demandas judiciales interminables, que absorben tiempo y recursos, desconectada de la realización de los intereses de los ciudadanos y, principalmente, teniendo en cuenta que los costos de una condena son superiores a los necesarios para el cumplimiento espontáneo de sus que el diálogo, con el uso de la conciliación y la mediación, pueden ser mecanismos de gran utilidad ${ }^{73}$.

La actuación dialogada requiere el establecimiento previo de procedimientos y procesos administrativos más transparentes para que se prevean las condiciones de diálogo, participación y decisión de forma justa y equitativa, mediante distintos mecanismos. ${ }^{74}$ Se trata de la Administración del siglo XXI, procedimentalizada, en la cual el procedimiento administrativo gana destaque, con la ponderación de los diversos valores e intereses involucrados, como consecuencia del Estado de Derecho, Democrático y Social ${ }^{75}$.

68 FUNGHI, Luís Henrique Baeta (2011), p. 10. También se posiciona OLIVEIRA, Rafael Carvalho Rezende (2015), p. 66.

69 HACHEM, Daniel Wunder, (2014), p. 259.

70 HACHEM, Daniel Wunder, (2014), p. 291.

71 HACHEM, Daniel Wunder, (2014), pp. 297, 318. El STF ya se posicionó favorablemente en el RE 253.885 / MG, en el cual admitió la transacción realizada entre un Municipio y sus servidores, incluso sin previsión legal expresa autorizativa para la celebración de acuerdos administrativos. Además, se admitió la atenuación del principio de la indisponibilidad del interés cuando se tiene en vista que la solución adoptada mejor lo atenderá. (RE 253885, Ponente: Min. ELLEN GRACIE, Primera Clase, Juzgado el 04/06/2002, DJ 21-06-2002 PP-00118 EMENT VOL-02074-04 PP-00796).

72 En este sentido, por ejemplo, en el área de la salud, el suministro de medicamentos, internamientos en la red privada cuando no hay camas disponibles en el SUS, como resalta HACHEM, Daniel Wunder (2014), pp. 480-481.

73 SOUZA, Luciane Moessa de (2008), p. 143.

74 CASEMIRO, Lígia Maria Mello de (2007), p. 119.

75 BITENCOURT NETO, Eurico (2017), pp. 212-213.

SCHUHLI BOURGES, Fernanda. Administración Pública dialógica: en busca de la concretización isonómica de derechos fundamentales en Brasil. Revista Justicia y Derecho, Santiago, v. 2, n 2, 2019 
Es por el procedimiento que la Administración tendrá la posibilidad de reunir informaciones y ponderaciones de diversos segmentos para actuar de modo más efectivo y legítimo, pues los propios particulares tendrán contacto con la existencia de diversas demandas y soluciones y tendrán conocimiento de los motivos que condujeron a la adopción de una determinada providencia ${ }^{76}$.

La participación dialogada y consensual administrativa puede ocurrir, sin embargo, en diversos momentos de la actuación administrativa: decisión, ejecución o función judicial administrativa ${ }^{77}$. El derecho brasileño ha consagrado una serie de posibilidades de participación democrática y consensuada de la colectividad en la gestión pública, tales como en la seguridad social, en la enseñanza pública, en consultas públicas y medidas consensuadas en el ámbito especializado regulatorio ${ }^{78}$. Entre las modalidades de participación administrativa ganan destaque las audiencias públicas, con previsión en el art. 32 de la Ley no 9.784/1999, así como en otras leyes específicas, permiten que cualquier persona/entidad sea oída y exponga sus necesidades y sugerencias cuando determinada decisión afecte sus intereses individuales, difusos o colectivos, de modo que la Administración podrá realizar mejor los derechos involucrados y tomar decisiones con mayor aceptación consensual79.

La consulta pública, prevista en el art. 31 de la Ley no 9.784 / 1999, también es un instrumento de cuestionamiento a la opinión pública, que posibilita participación de interesados, perfeccionamiento y legitimación de la actuación administrativa.

Los consejos municipales representan otro mecanismo de participación de la colectividad y diálogo con el Poder Público, traduciéndose en la "más alta correspondencia al modelo de gestión pública compartida, así como al principio democrático"80. El consenso en la función judicial se centra en la prevención y la resolución de conflictos y puede ocurrir por intermedio de las comisiones de conflicto ${ }^{81}$, de los acuerdos sustitutivos ${ }^{82}$, así como por conciliación, mediación, arbitraje, y similares.

La utilización de los mecanismos de participación permite las negociaciones y, por lo tanto, las decisiones administrativas se establecen a partir de la ponderación y, especialmente, mediante la reciprocidad de concesiones, ya que todos los partícipes ceden en algunos aspectos para que se obtenga la armonización de intereses hasta entonces contrapuestos ${ }^{83}$. La solución negociada de los litigios es un relevante instrumento para la efectividad de los derechos difusos y colectivos, sin demandar un largo y tortuoso proceso judicial, aún, reduce costos y anticipa a la sociedad los beneficios y el usufructo de los derechos fundamentales ${ }^{84}$.

Con el fin de perfeccionar el consenso y reducir el número de demandas judiciales, el Nuevo Código de Proceso Civil, Ley 13.105 / 2015, primó por la solución consensuada de los conflictos y estableció

76 XAVIER, Gabriela Costa (2014), p. 38.

77 El presente estudio, por su brevedad, no abordará detalladamente todas las fases y mecanismos posibles. La propuesta es presentar la existencia de posibilidades dialógicas a la Administración con el fin de concreción de derechos fundamentales sociales.

78 Arts. 194, VII, 198, III, 206, VI, 37, §3², de la Constitución de la República. En las agencias regulatorias: ANEEL, art. $3^{\circ}$, V. de la Ley n 9.427/1966; ANATEL, art. 19, XVII, de la Ley n 9.427/1997; ANP, art. 20, de la Ley n 9.478/1997; ANTT y ANTAQ, arts. 20, Il, b, y 29, II, b, de la Ley n 10.223/2001.

79 FUNGHI, Luís Henrique Baeta (2011), p. 12.

80 BITENCOURT, Caroline Müller y BEBER, Augusto Carlos de Menezes (2015), p. 249.

81 MAIA, Taciana Mara Corrêa (2014); A respeito MOREIRA NETO, Diogo de Figueiredo, (2003), pp. 152-155.

82 De acuerdo con Diogo de Figueiredo Moreira Neto, las comisiones de conflicto son permanentes para actuar siempre que haya la posibilidad y inminencia de instaurar un conflicto de intereses en el ámbito de su competencia. MOREIRA NETO, Diogo de Figueiredo, (2003), pp. 129-156.

83 OLIVEIRA, Gustavo Justino de (2008), p. 8.

84 BADIN, Arthur Sánchez (2009), pp. 195, 99-200.

SCHUHLI BOURGES, Fernanda. Administración Pública dialógica: en busca de la concretización isonómica de derechos fundamentales en Brasil. Revista Justicia y Derecho, Santiago, v. 2, n 2, 2019 
diversos mecanismos en este sentido. Además del Consejo Nacional de Justicia presentar como meta la reducción de demandas repetitivas y de grandes demandados, como el Poder Público ${ }^{85}$. En este sentido fue editada la Ley de Mediación, n. 13.140/2015.

De este modo, se tiene que la Administración Pública necesita de revisión en sus modos y mecanismos de actuación, que se muestran desactualizados e incompatibles con el Estado Democrático y Social de Derecho, consagrado en la Constitución de la República de 1988. La propuesta de adopción de instrumentos dialógicos en la gestión pública, con procedimientos de participación de los diversos segmentos sociales, además de concretar la cláusula democrática, posibilita la definición y la realización de los intereses públicos de modo más perfeccionado, participativo y real.

La Administración, al oír y contar con la participación de los individuos y de la colectividad, tiene la oportunidad de aferir las reales necesidades, así como las posibles y más efectivas soluciones a fin de concretar isonomicamente los derechos fundamentales sociales. De este modo, la adopción de un modelo de gestión pública dialógica tiene gran potencialidad al perfeccionamiento de la concreción de derechos fundamentales sociales en términos isónomicos, tanto en su dimensión subjetiva, como, especialmente, en la objetiva.

\section{Consideraciones finales}

En un Estado Social y Democrático de Derecho, fundado en la dignidad de la persona humana y que tiene como objetivo fundamental la reducción de las desigualdades, así como la erradicación de la pobreza y la marginación y la promoción del desarrollo, la Administración Pública está adscrita a concretar tales objetivos y, por lo tanto, a la realización de los derechos fundamentales sociales, principalmente en vista del reconocimiento de su aplicabilidad inmediata.

Sin embargo, a partir de la intensa judicialización de los derechos fundamentales sociales, se diagnostica que la actuación administrativa aún no es satisfactoria. Además, la concreción de derechos fundamentales sociales por el Poder Judicial tiende a ser restringida y circunstancial y, así, puede ocasionar efectos perjudiciales a la efectiva concreción de estos derechos.

Con la judicialización de los derechos fundamentales, muchas veces el Poder Judicial pasa a concretar, en vista de los datos del caso traído a los autos, el contenido y el alcance de las respectivas normas, que tienden a presentar elevado grado de abstracción. Ocurre que, sólo aquellos que ingresaron en juicio obtienen las ventajas y la concreción de los derechos de tal modo. Otros individuos o grupos poseedores de la misma posición jurídica subjetiva no serán beneficiarios del mismo contenido o, incluso, se les va a destinar alguna providencia.

La aplicación de los derechos fundamentales sociales por parte de la judicatura, aunque a menudo es la única alternativa del individuo, tiende a perjudicar la isonomía ya referirse sólo a la dimensión subjetiva de los derechos del demandante, de modo que la dimensión objetiva de estos derechos aún queda sin concretarse. Sin referirse aún al alcance de las decisiones, que tienden a ser circunstanciales e inmediatas, desprovistas de programación y continuidad, he aquí que éste no es el papel del Judiciario.

85 En el Informe "JUSTIÇA EM NÚMEROS 2015 (ano base 2014)" el CNJ presenta que en 2014 había en el Judicario Estadual de primer grado 2.288.055 y en el segundo grado 449.482 demandas contra el Poder Público, fls. 463 y 466 . En el Judicial Federal 3.044.233 en el primer grado y 922.650 en el segundo grado, fls. 301 y 303. Disponible en: http://www.cnj.jus.br/programas-e-acoes/pj-justica-em-numeros, acceso en 09 de octubre de 2016.

SCHUHLI BOURGES, Fernanda. Administración Pública dialógica: en busca de la concretización isonómica de derechos fundamentales en Brasil. Revista Justicia y Derecho, Santiago, v. 2, n², 2019 
Así, surge la necesidad de revisar la actuación de la Administración Pública en pro de la concreción administrativa e isonómica de los derechos fundamentales sociales. Ante la cláusula constitucional democrática, así como de la heterogeneidad social, con demandas y potenciales soluciones más específicas y complejas, se hace indispensable la participación de los diversos segmentos sociales, mediante variados procedimientos dialógicos, a fin de perfeccionar la definición y la realización de los intereses públicos, así como la concreción legítima e isonómica de los derechos fundamentales sociales en las dimensiones subjetiva y objetiva, es decir, independientemente de la provocación.

Se defiende, por lo tanto, un nuevo "modelo administrativo de gestión, es decir, lo que crea condiciones (objetivas y subjetivas) para la participación política de la ciudadanía como condición de una administración pública democrática"86 y comprometida con la realización de los derechos fundamentales sociales.

La propuesta de una gestión pública dialógica, que se utilice de procedimientos de diálogo previamente establecidos, sea en lo que se refiere a la decisión, ejecución y en la solución de controversias administrativas o judiciales, permite la identificación de las reales necesidades colectivas y de las posibles soluciones, de modo holístico y legítimo, muy diferente de una imposición unilateral, muchas veces desprendida de la realidad. Además, se añade a la concreción de la Constitución, con gran potencialidad de realización de los derechos fundamentales sociales anticipada e isonomicamente.

\section{Bibliografía Citada}

ALEXY, Robert (2014): Teoria dos direitos fundamentais. (São Paulo, Malheiros, 2 ed.).

ALEXY (2007): Teoría de los derechos fundamentales. (Madrid: Centro de Estudios Políticos y Constituciona-

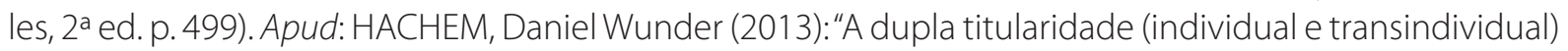
dos direitos fundamentais econômicos, sociais, culturais e ambientais", en Revista Direitos Fundamentais \& Democracia (UniBrasil), v. 14, n. 14.1, Curitiba, UniBrasil, pp. 618-688, ago./dez.

BACELLAR FILHO, Romeu Felipe (2007): Direito administrativo e o novo código civil. (Belo Horizonte, Fórum).

BACELLAR FILHO, Romeu Felipe (2014): "Dignidade da pessoa humana, direitos fundamentais e Direito Administrativo", en Revista Eurolatinoamericana de Derecho Administrativo, Santa Fe, vol. 1, n. 2, pp. 247254, jul./dic.

BADIN, Arthur Sanchez (2009): "Conselho Administrativo de Defesa Econômica (Cade). A transação judicial como instrumento de concretização do interesse público", en Revista de Direito Administrativo, vol. 252, setembro/dezembro, pp. 189-217. Rio de Janeiro: FGV.

BARBOZA, Estefânia Maria de Queiroz (2007): Jurisdição Constitucional: entre o constitucionalismo e a democracia (Belo Horizonte, Fórum).

BITENCOURT, Caroline Müller (2013): Controle jurisdicional de políticas públicas. (Porto Alegre, Núria Fabris Editora).

BITENCOURT, Caroline Müller y BEBER, Augusto Carlos de Menezes (2015): "O controle social a partir do modelo da gestão pública compartida: da insuficiência da representação parlamentar à atuação dos conselhos populares como espaços públicos de interação comunicativa", en Revista de Direito Econômico

86 BITENCOURT, Caroline Müller y PASE, Eduarda Simonetti (2015), p. 309.

SCHUHLI BOURGES, Fernanda. Administración Pública dialógica: en busca de la concretización isonómica de derechos fundamentales en Brasil. Revista Justicia y Derecho, Santiago, v. 2, n 2, 2019 
e Socioambiental, Curitiba, v. 6, n. 2, pp. 232-253, jul./dez. 2015. doi: http://dx.doi.org/10.7213/rev.dir.econ. socioambienta.06.002.A009

BITENCOURT, Caroline Müller y PASE, Eduarda Simonetti (2015): "A necessária relação entre democracia e controle social: discutindo os possíveis reflexos de uma democracia "não amadurecida" na efetivação do controle social da administração pública", en Revista de Investigações Constitucionais, Curitiba, vol. 2, n. 1, p. 293-311, jan./abr. 2015. DOl: http://dx.doi.org/10.5380/rinc.v2i1.43663

BITENCOURT NETO, Eurico (2017): "Transformações do Estado e a Administração Pública no século XXI", en Revista de Investigações Constitucionais, Curitiba, vol. 4, n. 1, p. 207-225, jan./abr. 2017. DOI: 10.5380/ rinc.v4i1.49773.

CARVALHO, Flávia Martins de, VIEIRA, José Ribas y RÉ, Mônica Campos de (2009). As teorias dialógicas e a democracia deliberativa diante da representação argumentativa do Supremo Tribunal Federal. Revista Internacional de Direito e Cidadania, n. 5, p. 81-92, outubro/2009. Disponível em: <http://www.buscalegis. ufsc.br/revistas/files/anexos/33307-42498-1-PB.pdf>. Acesso em 23 de junho de 2017.

CASEMIRO, Lígia Maria Mello de (2007):"Novas perspectivas para o Direito Administrativo: a função administrativa dialogando com a juridicidade e os direitos fundamentais sociais", en A\&C R. de Dir. Administrativo \& Constitucional, Belo Horizonte, ano 7, n. 30, p. 109-130, out./dez. 2007.

Conselho Nacional de Justiça. JUSTIÇA EM NÚMEROS 2015 (ano base 2014). Disponível em: http://www. cnj.jus.br/programas-e-acoes/pj-justica-em-numeros, acesso em 09 de outubro de 2016.

FUNGHI, Luís Henrique Baeta (2011): "Da dogmática autoritária à administração pública democrática”, en RDA - Revista de Direito Administrativo, Belo Horizonte, ano 2011, n. 257, maio/ago. 2011.

HACHEM, Daniel Wunder (2014): Tutela administrativa efetiva dos direitos fundamentais sociais: por uma implementação espontânea, integral e igualitária. Curitiba, 2014. 614 f. Tese (Doutorado) - Programa de Pós-Graduação em Direito, Universidade Federal do Paraná.

ACHEM, Daniel Wunder (2013a): "A dupla titularidade (individual e transindividual) dos direitos fundamentais econômicos, sociais, culturais e ambientais", en Revista Direitos Fundamentais \& Democracia (UniBrasil), v. 14, n. 14.1, Curitiba, UniBrasil, pp. 618-688, ago./dez. 2013.

HACHEM, Daniel Wunder (2013b): "A maximização dos direitos fundamentais econômicos e sociais pela via administrativa e a promoção do desenvolvimento", en Revista Direitos Fundamentais \& Democracia (UniBrasil), v. 13, n. 13, Curitiba, UniBrasil, pp. 340-399, jan./jul. 2013.

MAIA, Taciana Mara Corrêa (2014): "A administração pública consensual e a democratização da atividade administrativa", en Revista Jurídica UNIGRAN, Dourados, MS | v. 16 | n. 31 | Jan./Jun. 2014.

MEDAUAR. Odete (2003): O direito administrativo em evolução (São Paulo, Revista dos Tribunais, 2a ed.).

MOREIRA NETO, Diogo de Figueiredo (2003): "Novos institutos consensuais da ação administrativa", en Revista de Direito Administrativo, 231, Rio de Janeiro, Jan/Mar, 2003.

NOVAIS, Jorge Reis (2010): Direitos sociais: teoria jurídica dos direitos sociais enquanto direitos fundamentais (Coimbra, Coimbra Editora).

NOVAIS, Jorge Reis (2003): As restrições aos direitos fundamentais não expressamente autorizadas pela Constituição (Coimbra, Coimbra Editora).

OLIVEIRA, Gustavo Justino de (2008): "Administração pública democrática e efetivação de direitos fundamentais", en Fórum Administrativo - Direito Público - FA, Belo Horizonte, ano 8, n. 88, jun. 2008. Disponível 
em: <http://www.bidforum.com.br/bid/PDI0006.aspx?pdiCntd=53908>. Acesso em: 14 ago. 2017.

OLIVEIRA, Gustavo Justino de y SCHWANKA, Cristiane (2009): "A administração consensual como a nova face da administração pública no séc. XXI: fundamentos dogmáticos, formas de expressão e instrumentos de ação", en Revista da Faculdade de Direito da Universidade de São Paulo, v. 104, pp. 303 - 322, jan./ dez. 2009.

OLIVEIRA, Rafael Carvalho Rezende (2015): "A arbitragem nos contratos da Administração Pública e a Lei no 13.129/2015: novos desafios", en Revista Brasileira de Direito Público - RBDP, Belo Horizonte, ano 13, n. 51, pp. 59-79, out./dez. 2015.

PIVETTA, Saulo Lindorfer (2010): "Políticas públicas e a construção do conteúdo material do direito à saúde: desafio à Administração Pública brasileira", en A \& C Revista de Direito Administrativo \& Constitucional, Belo Horizonte, ano 10, n. 41, jul./set. 2010. Disponível em: <http://www.bidforum.com.br/bid/PDI0006. aspx?pdiCntd=69224>. Acesso em: 14 ago. 2017.

RIVERO, Antole; CAMARATTA, Martín (2015): "Nuevos paradigmas desde la Administración Pública para la tutela efectiva de los derechos económicos, sociales y culturales", en Revista Eurolatinoamericana de Derecho Administrativo, Santa Fe, vol. 2, n. 2, pp. 123-142, jul./dic. 2015. DOl: www.dx.doi.org/10.14409/ rr.v2i2.5167

ROCHA, Cármen Lúcia Antunes (2002): Democracia, Constituição e Administração Pública. A\&C Revista de Direito Administrativo \& Constitucional. n. 9, pp. 91-102.

RODRÍGUEZ-ARANA MUÑOZ, Jaime (2012): "Sobre el derecho fundamental a la buena administración y la posición jurídica del ciudadano", Revista de Direito Administrativo \& Constitucional. Ano 12, n. 47, jan/mar. 2012, pp. 13-50. Belo Horizonte: Fórum.

RODRÍGUEZ-ARANA MUÑOZ, Jaime (2015a): "Dimensiones del Estado Social y derechos fundamentales sociales", en Revista de Investigações Constitucionais, Curitiba, vol. 2, n. 2, pp. 31-62, maio/ago. 2015. DOI: http://dx.doi.org/10.5380/rinc.v2i2.44510.

RODRÍGUEZ-ARANA MUÑOZ, Jaime (2015b): "El Derecho Administrativo ante la crisis (el Derecho Administrativo Social)", en Revista Eurolatinoamericana de Derecho Administrativo, Santa Fe, vol. 2, n. 2, p. 7-30, jul./dic. 2015. DOl: www.dx.doi.org/10.14409/rr.v2i2.5161.

SARLET, Ingo Wolfgang y FIGUEIREDO, Mariana Filchtiner (2010): "Reserva do possível, mínimo existencial e direito à saúde: algumas aproximações", en SARLET, Ingo Wolfgang; TIMM, Luciano Benetti (Coords.). Direitos fundamentais: orçamento e "reserva do possível" (Porto Alegre, Livraria do Advogado, 2a ed.) pp. 13-50.

SCHWANKA, Christiane (2011): "A processualidade administrativa como instrumento de densificação da administração pública democrática: a conformação da administração pública consensual", en Revista do Tribunal de Contas do Estado de Minas Gerais, julho | agosto | setembro 2011 | v. 80 - n. 3 — ano XXIX.

SOUZA, Luciane Moessa de (2008): "O papel da advocacia pública no Estado Democrático de Direito: da necessidade de sua contribuição para o acesso à justiça e o desenvolvimento institucional", en $A \& C$ - Revista de Direito Administrativo \& Constitucional, n 34, Belo Horizonte, Fórum, pp. 141-174, out./dez. 2008.

SOUZA JÚNIOR, Cezar Saldanha (2002): O tribunal constitucional como poder. Uma nova teoria da divisão dos poderes. São Paulo: Memória Jurídica Editora.

VALLE, Vanice Regina Lírio do (2016): Políticas públicas, direitos fundamentais e controle judicial (Belo Horizonte, Fórum, $2^{\mathrm{a}}$ ed.).

SCHUHLI BOURGES, Fernanda. Administración Pública dialógica: en busca de la concretización isonómica de derechos fundamentales en Brasil. Revista Justicia y Derecho, Santiago, v. 2, n², 2019 
XAVIER, Gabriela Costa (2014): "Novos rumos da Administração Pública eficiente - Participação administrativa, procedimentalização, consensualismo e as decisões colegiadas", en Fórum Administrativo - FA, Belo Horizonte, ano 14, n. 159, pp. 33-43, maio 2014.

\section{NORMAS CITADAS}

Constitución da República Federativa de Brasil, 1988;

Código de Proceso Civil;

Ley de Mediación, n. 13.140/2015;

Ley de Proceso Administrativo, Ley 9.784/1999.

\section{JURISPRUDENCIA CITADA}

BRASIL. Supremo Tribunal Federal. Recurso Extraordinário n²53885/MG. Relatora Min. ELLEN GRACIE, Primeira Turma, julgado em 04/06/2002, DJ 21-06-2002 PP-00118 EMENT VOL-02074-04 PP-00796.

SCHUHLI BOURGES, Fernanda. Administración Pública dialógica: en busca de la concretización isonómica de derechos fundamentales en Brasil. Revista Justicia y Derecho, Santiago, v. 2, n², 2019 